\title{
COMPARISON OF "HIGH THROUGHPUT" MICROMETHODS FOR DETERMINATION OF CYTOCHROME P450 ACTIVITIES WITH CLASSICAL METHODS USING HPLC FOR PRODUCT IDENTIFICATION
}

\author{
Eva Anzenbacherováa ${ }^{a}$ Alena Veinlichováb, Vlastimil Mašek ${ }^{b}$, Pavel Anzenbacher ${ }^{b}$ \\ a Institute of Medical Chemistry and Biochemistry, Faculty of Medicine, Palacky University, Hnèvotínská 3, \\ 77515 Olomouc, Czech Republic \\ ${ }^{b}$ Institute of Pharmacology, Faculty of Medicine, Palacky University, Hnèvotínská 3, 77515 Olomouc, Czech Republic \\ e-mail:anzeneva@tunw.upol.cz
}

Received: June 10, 2005; Accepted: September 25, 2005

Key words: Cytochrome P450/CYP/Luminiscence/Fluorescence/HPLC

Enzyme activities of the CYP enzymes (CYP3A4, CYP2C9 and CYP2A6) were determined using classical substrates (testosterone, diclofenac and coumarin, respectively) as well as with luminogenic or fluorogenic substrates in micromethod arrangement. The luciferin-based luminogenic substrates for CYP3A4 and CYP2C9 as well as coumarin in micromethod for assay of CYP2A6 activity gave results well comparable with the classical methods with determination of reaction products by the HPLC.

\section{INTRODUCTION}

Cytochromes P450 (CYP) are one of the most intensively studied heme enzymes thanks to their ability to convert variety of substrates to more polar derivatives. Their activities are intimately connected with metabolism of drugs, with metabolic activation of carcinogens as polycyclic aromatic hydrocarbons or nitrosamines as well as with biosynthetic pathways leading to formation of e.g. steroid hormones or prostaglandins ${ }^{1}$. Among fifty seven human cytochrome P450 forms, focus is given to these present in human liver and active in metabolism of majority of foreign substances as drugs or, in general, of xenobiotics ${ }^{2}$.

To characterize an individual CYP enzyme (form) and to have a tool for evaluation of its role in drug metabolism in man, a reliable method for determining of its enzyme activity is needed. A substrate used in such a method should be sufficiently specific; the method should be quick and robust and, in the optimal way, should allow for routine evaluation of many samples in parallel. Established methods for determination of activities of CYP forms are given in the literature ${ }^{3}$. However, the need for rapid and "high throughput" methods resulted in development of micromethods based on spectroscopic properties of the reaction mixtures (absorption, fluorescence, luminescence) with either "classical" substrates or with newly designed and validated more or less specific substrates. The aim of this work is to present a comparison of methods for determination of three CYP forms, CYP3A4, CYP2C9 and CYP2A6 based on determination of reaction products by HPLC with methods of high throughput based on determination of sample luminescence or fluorescence using standard microplates.

\section{MATERIAL AND METHODS}

\section{Materials}

All common laboratory chemicals were purchased from Sigma (Sigma Aldrich CZ, Prague) and were of reagent grade purity. Specific P450-Glo substrates for luminescence-based determination of CYP3A4 and CYP2C9 activity were products of Promega (Madison, WI) and were purchased from East Port (Prague, CZ). Human liver microsomes were purchased from Advancell (Barcelona, E).

\section{Methods}

CYP activities were determined using a Shimadzu Class VP HPLC system (Shimadzu, Tokyo, Japan) or Tecan Genios (Tecan, Mannedorf/Zurich, $\mathrm{CH}$, supplied by Schoeller Instruments, Prague, CZ) with 96 well microplates (Sarstedt, Nümbrecht, D). The classical methods with determination of reaction products by HPLC were: CYP3A4, testosterone 6ß-hydroxylase activity"; CYP2C9, 4'-hydroxylation of diclofenac ${ }^{5}$; CYP2A6, coumarin 7hydroxylation ${ }^{6}$. The respective protocols described in the original references were applied. Micromethods of CYP activity determination were based on liberation of free luciferin from the appropriate specific substrate (luciferin derivative) by action of the respective CYP form. The methods used were: CYP3A4, Promega P450$\mathrm{Glo}^{\mathrm{TM}}$ Assay with luciferin 6'-benzylether (Luciferin-BE); CYP2C9, Promega P450-GloTM Assay with 6'-deoxyluciferin (Luciferin-H); and CYP2A6, 7-hydroxylation of coumarin was followed by determination of fluorescence emission; classical method ${ }^{7}$ was adjusted for microplate use in our laboratory. For comparison, the approximate 
amount of CYP in the reaction mixture is less than 10 pmol of P450 in micromethods and 100 pmol of P450 in the classical methods. All data are averages from two determinations; to get the $K_{\mathrm{M}}$ and $V_{\mathrm{MAX}}$ parameters, the Sigma Plot v. 8.0 graphing and statistical software (SPSS, Chicago, IL) was used.

\section{RESULTS AND DISCUSSION}

\section{CYP3A4}

Enzyme kinetics of testosterone $6-\beta$ hydroxylation and of luciferin-based reaction obtained with human liver microsomes followed the Michaelis-Menten kinetics. Results of both experiments are shown in Fig.1; $K_{\mathrm{M}}$ and $V_{\text {MAX }}$ values are displayed in Table 1 . The $\mathrm{K}_{\mathrm{M}}$ values obtained with detection of reaction product by the HPLC and by the micromethod are in the same range, value of the $\mathrm{K}_{\mathrm{M}}$ for testosterone hydroxylation corresponds to those published in literature ${ }^{8}$. The $\mathrm{V}_{\text {MAX }}$ for the micromethod could be expressed in the relative luminescence units (RLU) only; however, an appropriate calibration would certainly yield values corresponding to product concentration. For the purpose of comparison, this form of expression is sufficient as the kinetics clearly followed the saturation (Michaelis) kinetics.

\section{CYP2C9}

The same approach as described above has been applied also to studies on the CYP2C9 enzyme kinetics. Both determinations of the enzyme kinetics, the classical one with diclofenac as well as the micromethod with 6'deoxyluciferin as substrates yielded a Michaelis-Menten kinetics (not shown) with the respective parameters presented in Table 1. Again, the $K_{\mathrm{M}}$ value obtained here fits to the range of the values expected for the CYP2C9 driven metabolism of diclofenac ${ }^{9}$.

\section{CYP2A6}

To determine the activity of this CYP enzyme, coumarin has been used in both analyses: with HPLC used for obtaining the levels of 7-hydroxycoumarin formed as
HPLC determination

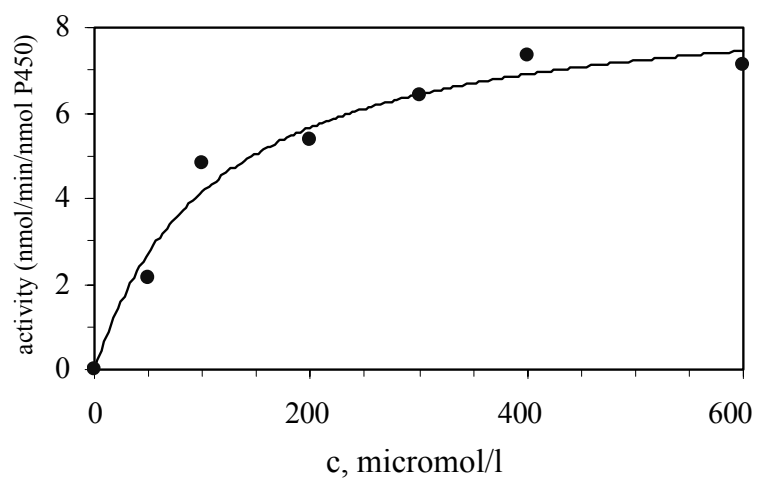

Luminescence

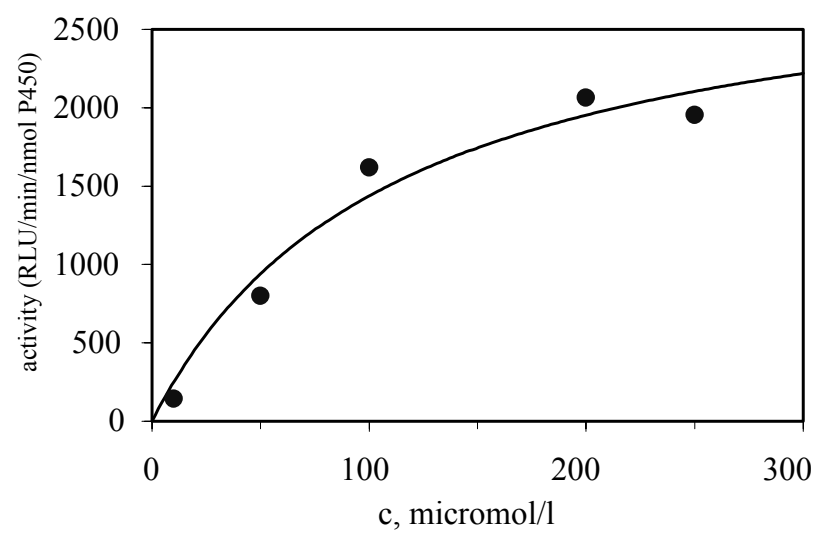

Fig. 1. CYP3A4 activity determination with substrate testosterone and HPLC detection of the reaction product (upper panel) and with the luciferin 6-benzylether and detection of luciferin formed by luminescence (lower panel).

Table 1. Michaelis-Menten kinetic parameters for three CYP enzyme activities determined by two methods with reaction products determined by HPLC or by micromethod

\begin{tabular}{|c|c|c|c|c|c|c|}
\hline & \multicolumn{2}{|c|}{ CYP3A4 } & \multicolumn{2}{c|}{ CYP2C9 } & \multicolumn{2}{c|}{ CYP2A6 } \\
\hline & HPLC & Micromethod & HPLC & Micromethod & HPLC & Micromethod \\
\hline$K_{\mathrm{M}}{ }^{\mathrm{a}}$ & 111.2 & 111.7 & 12.4 & 103.0 & 7.9 & 6.9 \\
\hline$V_{\mathrm{MAX}}{ }^{\mathrm{b}}$ & 8.8 & $(3044)$ & 5.22 & $(17713)$ & 4.2 & 0.83 \\
\hline
\end{tabular}

${ }^{\text {a }} K_{\mathrm{M}}$ values in $\mu \mathrm{M}$, ${ }^{\mathrm{b}} V_{\mathrm{MAX}}$ expressed as nmol product/min/nmol P450 for HPLC-based methods and for the micromethod for CYPA6; for CYP3A4 and CYP2C9 in micro arrangement, relative luminescence units/min/nmol P450 are given in parentheses 
well with the micromethod. Results are displayed in the Table 1 . The $K_{\mathrm{M}}$ values obtained were in this case rather close; the $V_{\mathrm{MAX}}$ values differ by factor of five which may be due to less robust analysis with the HPLC (variations in fluorescence response of the respective detector). Also, a lower value of the $K_{\mathrm{M}}$ obtained with the micromethod is closer to the values expected for this reaction?

In a summary, the high throughput methods based either on the recently introduced luciferin derivatives as specific substrates of CYP3A4 and CYP2C9 or on fluorescence are reliable giving enzyme kinetics of MichaelisMenten shape and parameters $\left(K_{\mathrm{M}}\right.$ and $\left.V_{\mathrm{MAX}}\right)$ in an acceptable range of values. However, the micromethods are quick and need considerably less material.

\section{ACKNOWLEDGEMENT}

The authors thank the Ministry of Education of the Czech Republic for supporting the MSM 6198959216 project.

\section{REFERENCES}

1. Anzenbacher P, Anzenbacherová E. (2001) Cytochromes P450 and metabolism of xenobiotics. CMLS, Cell Mol. Life Sci. 58, 737-47.

2. Guengerich FP, Human cytochromes P450. In: Ortiz de Montellano PR, editor. Cytochrome P450, structure, mechanism and biochemistry ( $3^{\text {rd }}$ Ed.). New York, Kluwer/Plenum Press, 2005. p. 377530.

3. Phillips IR, Shephard EA, editors. Cytochrome P450 Protocols (Meth Mol Biol 107). Totowa: Humana Press, 1998.

4. Guengerich, FP, Martin MV, Beaune PH, Kremers P, Wolff T, Waxman, DJ. (1986) Characterization of rat and human liver microsomal cytochrome $\mathrm{P} 450$ forms involved in nifedipine oxidation. J Biol Chem 261, 5051-60.

5. Crespi CL, Chang TKH, Waxman DJ. Determination of CYP2C9catalyzed diclofenac 4'-hydroxylation by HPLC. In: Ref. 3, p. 12933.

6. Souček P. (1999) Novel sensitive HPLC method for assay of coumarin 7-hydroxylation. J Chromatogr B 734, 23-9.

7. Waxman DJ, Chang TKH. Spectrofluorometric analysis of CYP2A6-catalyzed coumarin 7-hydroxylation. In: Ref. 3, p. 111-6.

8. Wang RW, Newton DJ, Scheri TD, Lu AY. (1997) Human cytochrome P450 3A4-catalyzed testosterone 6beta-hydroxylation and erythromycin $\mathrm{N}$-demethylation. Competition during catalysis. Drug Metab Disposition 25, 502-7.

9. Bort R, Mace K, Boobis A, Gomez-Lechon MJ, Pfeifer A, Castell J. (1999) Hepatic metabolism of diclofenac: role of human CYP in the minor oxidative pathways. Biochem Pharmacol 58, 787-96. 